\title{
Design of a web-based courseware authoring and presentation system
}

\author{
Engr. Prof Hyacinth C. Inyiama \\ Electronic and Computer Engineering Dept \\ Nnamdi Azikiwe University \\ Awka, Nigeria \\ Engr. Dr. Mrs. Christiana C. Okezie \\ Electronic and Computer Engineering Dept \\ Nnamdi Azikiwe University \\ Awka, Nigeria
}

\author{
Engr. Miss Chioma N. Anozie \\ Electronic and Computer Engineering Dept \\ Nnamdi Azikiwe University \\ Awka, Nigeria \\ Engr. Mrs. Nkolika O. Nwazor \\ Research and Development Department \\ Electronic Development Institute \\ Awka, Nigeria
}

\begin{abstract}
A Web-based Courseware Authoring and Presentation System is a user-friendly and interactive e-learning software that can be used by both computer experts and non-computer experts to prepare a courseware in any subject of interest and to present lectures to the target audience in full media. The resultant courseware is accessed online by the target audience. The software features automated assessment and grading of students. Top-down methodology was adopted in the development of the authoring software. Implementation languages include Asp.Net and Visual Basic 9.0 and Microsoft Access 2007. An author can use the system to create a web-based courseware on any topic of his choice, while the software platform still remains intact for yet another author. A major contribution of this work is that it eases courseware preparation and delivery for lecturers and trainers.
\end{abstract}

Keywords- Web; Courseware; Authoring; Presentation; ELearning; Multimedia.

\section{INTRODUCTION}

Paper and pencil correspondence courses have been available for over fifty years, and for motivated students, have been proven to work adequately. However, today's educators of college and university students face new challenges related to the increasing demand for provision of course related resources and documents due to the geometric surge in the population of students in tertiary institutions. Traditional blackboard and paper tutorship is proving to be an inadequate method of ensuring effective learning and assimilation amongst a multitude of students. Also there is a high demand for distance learning in today's information age which cannot be met by traditional method.

Tertiary institutions in some of the developing and underdeveloped nations like Nigeria have not only experienced a tremendous increase in the number of students enrolled yearly but have also experienced the disruption of normal school session frequently by strikes. This vast number and the frequent disruption of normal school session have made it difficult for the few lecturers there are to lecture and assess students effectively. Hence there is need for an e-learning solution that enables lecturers to effectively teach and assess students irrespective of the permitted classroom time and the location of the students.

With the growth of information and communication technology, the advent of the world wide web and the introduction of e-learning technology, the development of a solution to extend the classroom to the internet and educate students on a one-on-one basis, is now possible [1]. The webbased courseware authoring and presentation system is such a solution and also incorporates a module for testing the student and hence assessing his performance. It also has an easy-to-use interface, hence ensuring that any lecturer can be an author of a courseware with minimal computer expertise.

\section{Problem Statement}

To establish the problem statement, the shortcomings of the present method of knowledge dissemination in most developing and under-developed nations (the traditional blackboard and paper system) were identified:

- A student misses a lot of information that cannot be easily passed to him by his fellow students if he is absent from or late to a lecture. This is because the lecturer, who is seasoned by years of experience, skills and education, knows exactly how to describe a topic and what elements to employ to accelerate understanding. Hence when a student misses a lecture, it becomes very difficult to understand the topic that was taught.

- Traditional blackboard lecture delivery method is not tailored to suit the different learning paces of the different students in a classroom.

- The unstable educational environments of tertiary institutions in these nations, caused by strikes and riots make it almost impossible for any lecturer to effectively teach all the topics in his course scheme of work. This poses a big problem as information is mostly relevant in its entirety and not as an incomplete piece. 
- The present system is not economical. This is because a lot of people who wish to be educated but are hindered because of distance cannot harness the power of education. Distance learning cannot be conducted in the traditional method of education.

\section{OBJECTIVE}

The objective of this paper is to present the design of a web-based courseware authoring and presentation system which is an e-learning system tailored to the needs and challenges (presented in the problem statement) of the educational environment in most developing and underdeveloped nations of the world.

\section{Definitions And Explanation Of Terms}

Courseware is a term that combines the words 'course' with 'software'. Its meaning originally was used to describe additional educational material intended as kits for teachers or trainers or as tutorials for students, usually packaged for use with a computer. The term's meaning and usage has expanded and can refer to the entire course and any additional material when used in reference to an online or 'computer formatted' classroom [1].

The technicalities involved in courseware production deter many teachers from utilizing this new technology. This lead to the development of authoring system for courseware production that will allow novice programmers to produce their own courseware packages [2]. An Authoring System allows a non-programmer to easily create a courseware without going through the rigors of developing the software and writing the codes. The programming features are built in but hidden behind buttons and other tools, so the author does not need to know how to program [3].

A Web-based authoring tool can be considered an elearning tool because it creates courseware that utilizes the web-hosting facility of the authoring software to be made available online, thereby enabling students to study over the internet irrespective of their location.

\section{SYSTEM OVER VIEW}

The web-based courseware authoring and presentation system is a platform that can be used by a lecturer/author with little technical skills but basic computer literacy. It is a platform that can be used for the courseware development of any topic or course and can be used multiple times. It is not designed specifically for any particular course and as such can be accessed by different course authors.

As shown in Fig.1, the web-based courseware authoring and presentation system for tertiary institutions has 3 main modules:

- The courseware production module

- The user module

- The online e-learning portal module
The courseware is developed with the aid of the courseware authoring software; it is then published on the web, from where it can be accessed by the appropriate user.

\section{A. The courseware Production}

This entails the pre-development of the courseware from course materials. This is normally done offline. Here the courseware author designs the outline of his course (which could be based on international, national or personal schemes). Based on the design, he then categories his work into the following divisions where appropriate:

- Objectives of his course

- The lecture notes/text that would accompany his course

- The lecture media that would shed further insight to his work

- The Quiz questions that would be used to test student's understanding of his course.

This is a very important stage of courseware production, for any failure or mistake in this pre-development stage will affect the final output of the finished courseware. It may lead to a situation where the intended content is not properly communicated to the students that will use the courseware hence defeating one of the aims of the web-based courseware authoring and presentation system. Text development packages like Microsoft notepad and video development packages like adobe flash are used at this stage to digitize course materials

\section{B. Users}

Users, in this context, refer to authorized or registered people with various degrees of access privileges. This means that access to the web-based courseware authoring and presentation system is limited to registered members. Also, the user's access privilege is determined by his role. The permissible roles in the web-based courseware authoring and presentation system are shown below:

- Lecturer/Author: this user has courseware creation rights as well as courseware presentation rights. Hence he can both create and view previously created courseware.

- Student: this user's access privilege is limited to viewing available courseware.

\section{Online E-learning}

This part embodies all events and transactions that occur over the internet. Hence $\log$ in of registered members, registration of new members, final development of predesigned courseware and courseware presentation are under this part. When a registered user logs in to the web-based courseware system, his access privileges are determined and if he has author rights, then upon feeding pre-design courseware materials into the system, the system saves them in the database, from where it can be retrieved for viewing purposes by all users. 


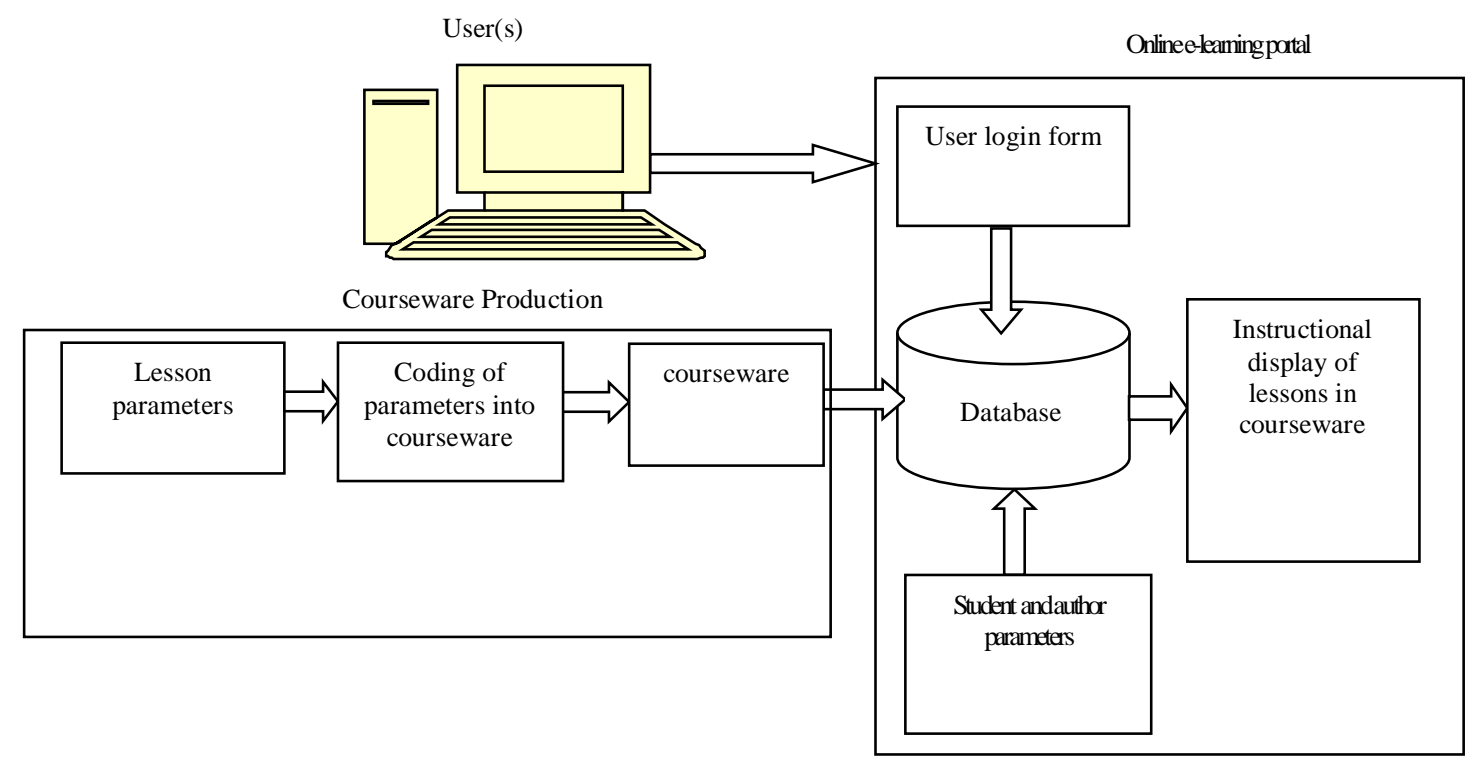

Figure 1. The block diagram representation of the web-based courseware authoring and presentation system for tertiary institutions.

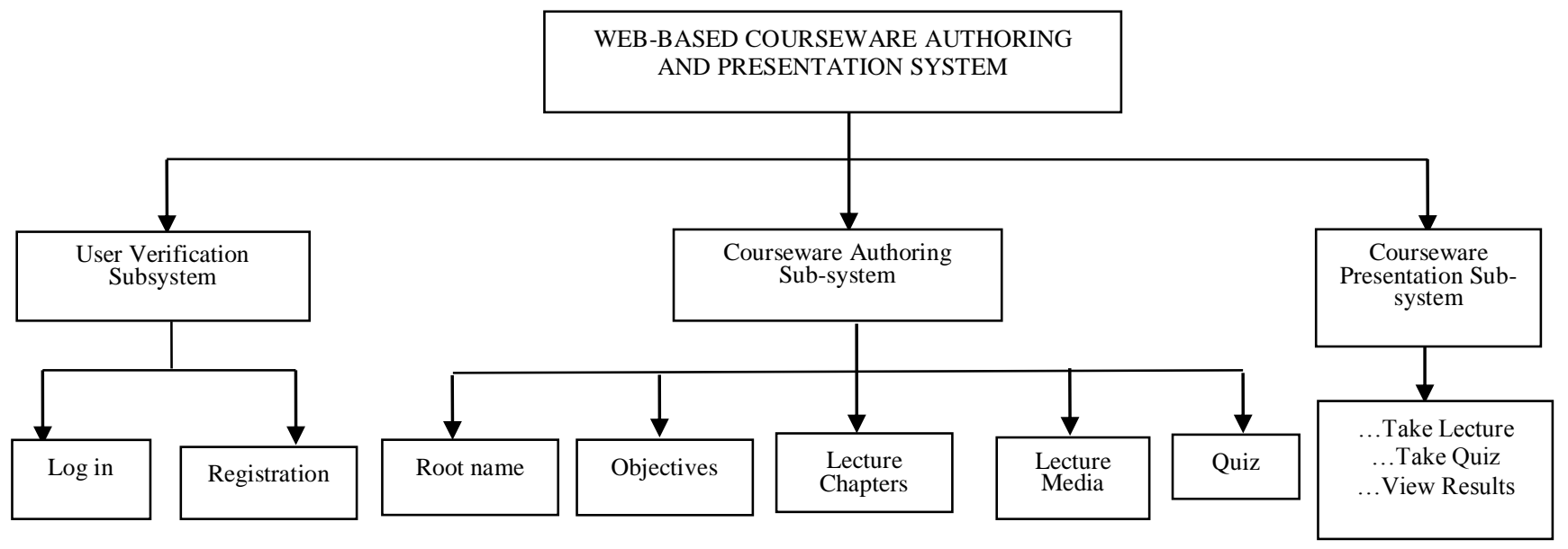

Figure 2. Top-down Design procedures for the Web-based Courseware Authoring and Presentation System

\section{DESIGN SPECIFICATION}

The top-down design of the web-based courseware authoring and presentation system (WCAPS) in high level model is shown in Figure2 to illustrate the system specification of the project.

\section{A. Software sub-systems}

The web-based courseware authoring and presentation system is grouped into four subsystems. These subsystems are further divided into modules. Asp.net and VB.net were combined to develop the courseware authoring and presentation system.

1) User verification subsystem: This subsystem has two modules: login module and registration module. It is the foremost subsystem encountered by a user. Access is granted to only those whose data are stored in the database; else the prospective user is redirected to the registration page. The lecturer table and the student table are utilized for the smooth operation of this subsystem. The flowchart of the user verification subsystem is shown in Fig3 and 4 


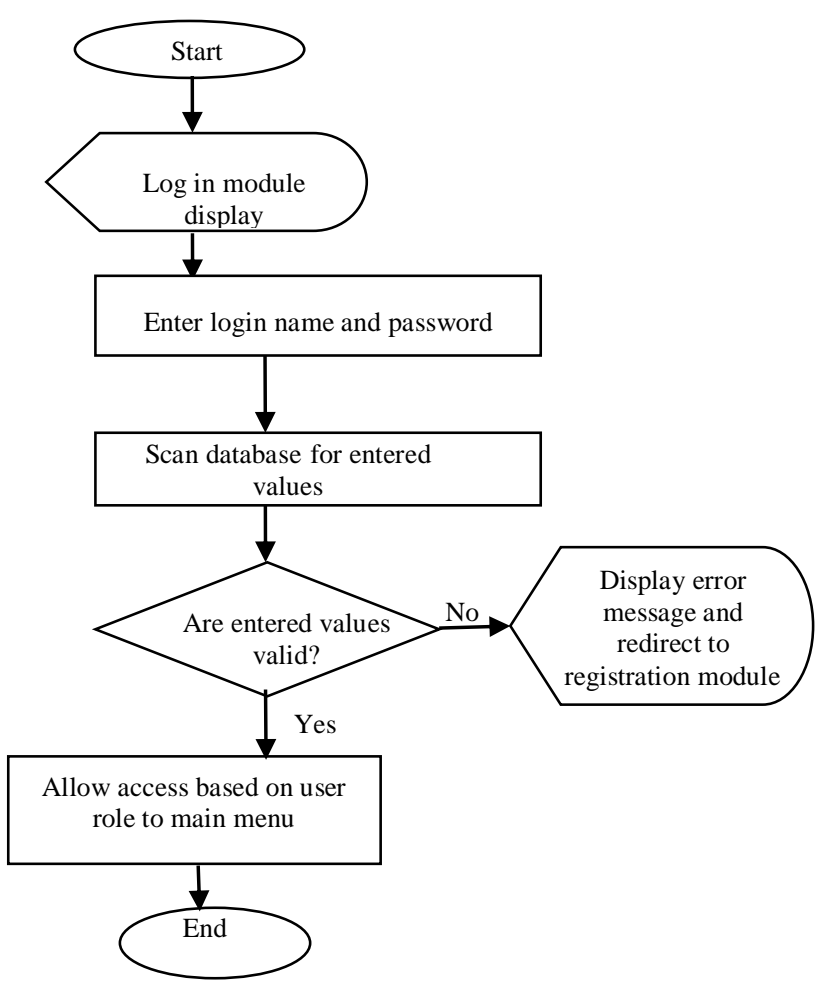

Figure 3. The flowchart representation of the log in module of the user verification subsystem

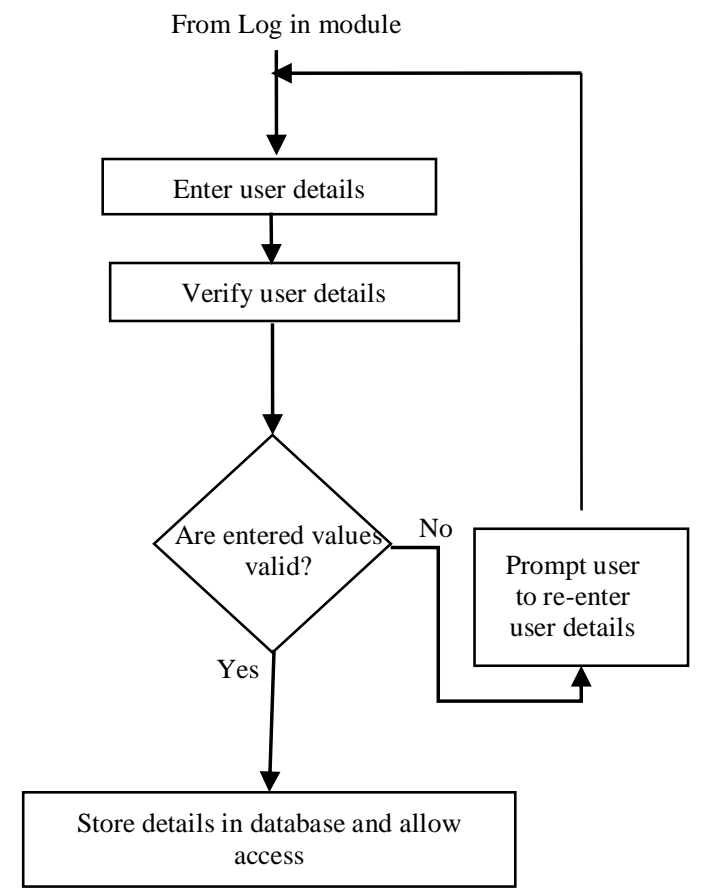

Figure 4. The flowchart representation of the registration module of the user verification subsvstem

2) Courseware authoring subsystem: In this subsystem, the lecturer/author is able to create his pre-designed courseware. At the beginning, the author supplies at prompting the materials/ parameters necessary for the development of his courseware. These include his identity data, the files necessary for the different modules of his course and the questions necessary for the quiz. This sub-system comprises of five modules: Rootname Generation module, Objectives module, Tutorial (lecture notes) module, Tutorial (media files), Quiz and Score module.

a) Rootname Generation module: The rootname for every courseware is coined from a concatenation of the author's name, courseware title, and courseware topic and courseware code. This way a unique name is formed for every courseware that is created irrespective of whether it is by the same author. The rootname is then stored in the courseware table with its corresponding courseware details (topic, author, title, code). Subsequently as the courseware author continues to the next stage, the rootname is used to save all entered data in their respective tables. This is done this way so that, when a courseware is requested, the courseware processor gets the rootname of the requested courseware from the courseware table and then goes to other tables and searches for the locations of files bearing this rootname and uploads those files to make the courseware functional.

b) Objectives module: This section is linked to the Objectives of the courseware, thereby stating what the aim of the courseware is and what a student should be equipped with after studying the courseware. The objectives file is uploaded from the client side computer and then stored in a server-side file called courseware items. The location of this objectives file in the server is saved to the objectives table against the current rootname.

c) Tutorial module: the tutorial module is divided into the lecture notes part and the media part. While the lecture notes (as the name implies) is culled from the lecturer's notes and/textbook, the media files are scenes captured during a lecturer's lecture. The media files help to further emulate the classroom experience. All these files are uploaded as well and saved in the server folder called courseware items. The respective locations of the files are saved in the chapters table (for the lecture notes) and the Multimedia table (for the lecture media) where appropriate, against the current rootname.

d) Question module: This section displays the questions associated to each tutorial topic. In this module, students are exposed to questions on the courseware topic and the answers associated to each question supplied as well. It serves as a good revision venue. During the development of the quiz, the quiz builder in the web-based courseware authoring and presentation system wizard is used to input questions and save them directly to the quiz table along with their options and the right answer. These questions are saved against the current rootname.

The objectives table, chapters table, multimedia table, quiz table and courseware table are used for all data storage in this subsystem. Fig.5 is the flowchart for the courseware authoring subsystem.

3) Courseware presentation Subsystem: This subsystem is comprised of a single module and entails a user-friendly 
interface for viewing available courseware. The flowchart is shown in Fig.6.

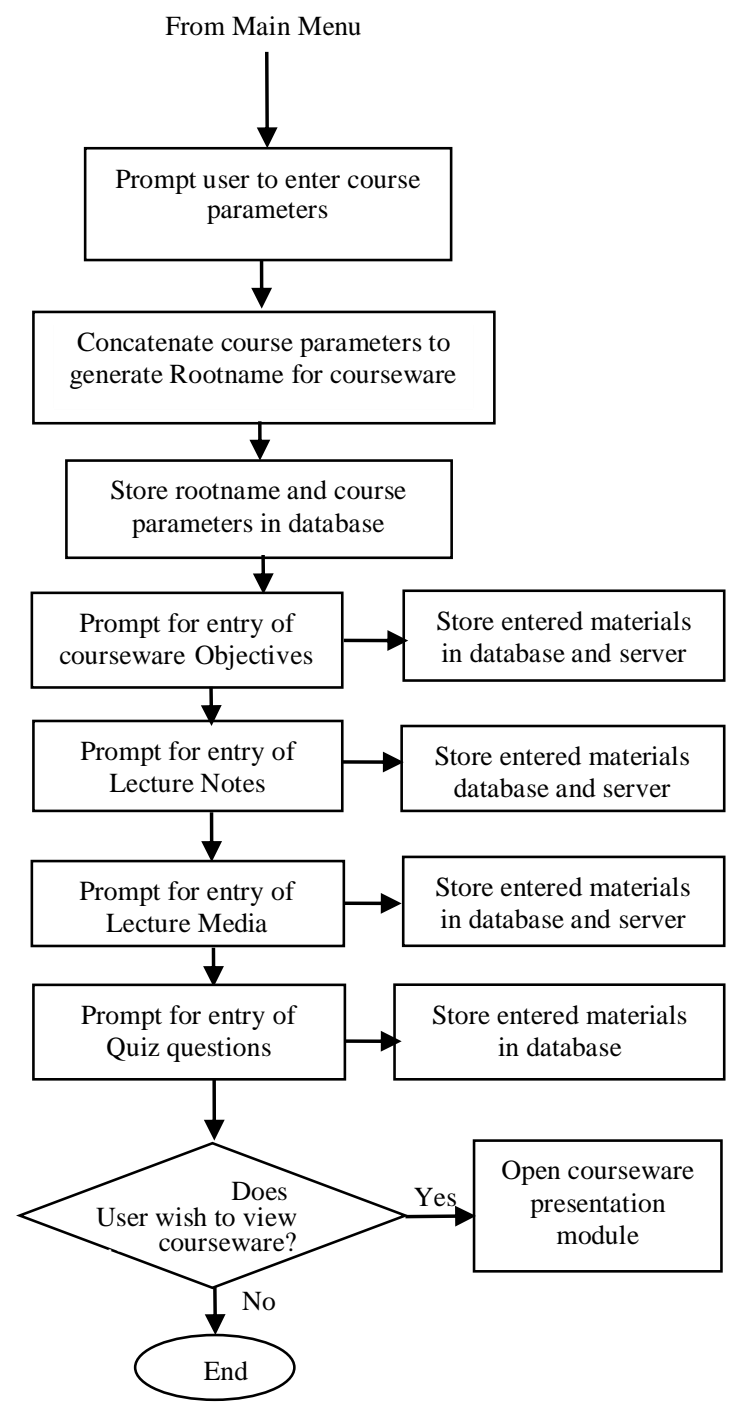

Figure 5. The flow chart of the courseware authoring subsystem

4) Database Specification: Database is a collection of logically related data. The Database Specifications are intended to support program coding and database generation by the development group. The database structure, content, data fields, and records were defined. The database for this project was designed using Microsoft Access 2007 database management system. The database of the structured logic design tutor has the following tables:

- Courseware Registration

- Lecturer

- Student

- Objectives

- Chapters
- Multimedia

- Quiz

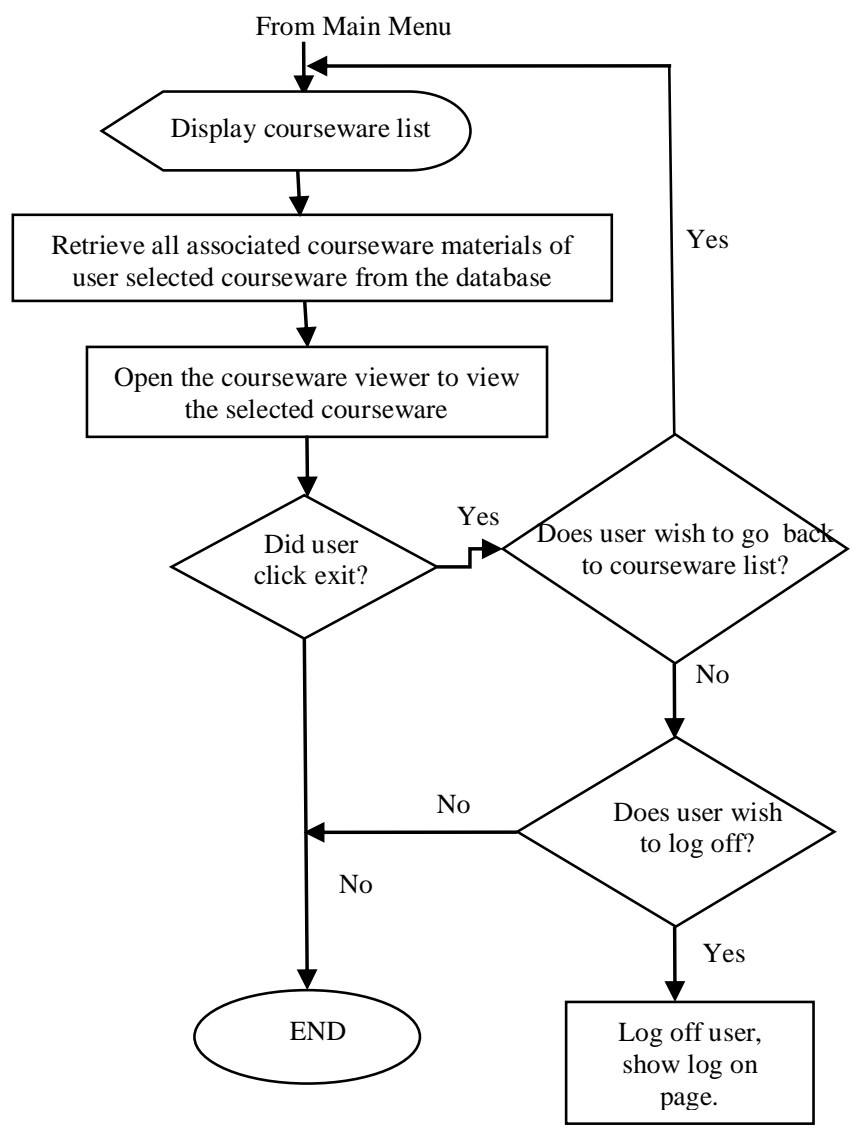

Figure 6. The flowchart of the courseware viewing subsystem

Table1 is a sample of the database table design used in the system

TABLE I. A TABLE DESIGN For COURSEWARE REGISTRATION

\begin{tabular}{|l|l|l|l|}
\hline \multicolumn{1}{|c|}{ FIELD NAME } & FIELD TYPE & FIELD SIZE & KEY \\
\hline CoursewareID & Autonumber & Long integer & $\begin{array}{l}\text { Primary } \\
\text { Key }\end{array}$ \\
\hline CoursewareAuthor & Text & 100 & \\
\hline CoursewareTitle & Text & 150 & \\
\hline CoursewareCode & text & 10 & \\
\hline Rootname & memo & & \\
\hline
\end{tabular}

\section{COMPARISON With Established COURSEWARE} AUTHORING SYSTEMS

There are some courseware's authoring systems available in the market. They include Authorware, Moodle to mention a few.

Authorware is an icon-based multimedia authoring tool which allows the rapid development of complex interactive 
multimedia projects, particularly courseware and kiosk applications, for both the Macintosh and Microsoft Windows operating systems.

It consists of three main elements: interactive courseware, written in Authorware, which teaches the student basic concepts involved in Authorware programming, and demonstrates the function of each of the icons used to program in Authorware; a tutorial through which students are given the opportunity to use Authorware to incorporate various media elements, including written audio, graphics, video, and text, into their own interactive courseware; and various course materials, including a statement of objectives, study questions, and quiz questions [4].

However, Authorware requires an understanding of its courseware development language. It also requires a license to use and buying it is steep. It also requires an installation process hence meaning that should the courseware author be in a different location and without access to his system, he can't create coursewares. The Web-Based Courseware Authoring System, though lacking the functional complexity of authorware, with its simplicity ensures an author can create coursewares irrespective of his location or access to his personal system. It also requires no knowledge of any programming language.

Moodle is a learning management system that lets you provide documents, graded assignments, quizzes, discussion forums, etc. to your students with an easy to learn and use interface. Moodle is open-source, meaning that the programming code that runs it can be changed to meet the specific needs of users and institutions. Moodle is also free to download and use; there is no licensing fee [5].

However, the drawback is the need to download Moodle to one's personal computer in order to create coursewares. The Web-Based Courseware Authoring System does not need an installation in a personal system. All it needs is internet access and valid authentication data.

\section{CONCLUSION}

During the period of this research work, the limitations of the traditional educational system predominantly used in developing and underdeveloped nations were identified. From there, the functional requirements of the web-based authoring system were developed. It was also necessary to put into consideration the limited programming expertise of the courseware authors. The system prototype was then compared with existing authoring systems like Authorware and Moodle. To ensure a robust system, Visual Basic.Net and Asp.Net was used to develop the Web-Based Courseware Authoring System due to their object-oriented architecture and robust development environment [6][7].

The web-based courseware authoring system was tested with different systems and browsers and it worked seamlessly whilst deploying expected results. However, it does have its shortfalls. In areas such as video conferencing, real-time online blackboard teaching, real-time question and answer forum using chat technology the Web-based Courseware Authoring System is lacking andtherefore further research in these areas is encouraged.

\section{REFERENCES}

[1] Routledge, E-Learning: A Framework For Research And Practice. ISBN $0-415-26346-8$

[2] Judi Johnson, (2003), Then, Now And Beyond.... A Look At The Past 30 Years Of Educational Software, Learning And Leading With Technology Volume 30 Number 7

[3] Mayer R.E (2001), Multimedia Learning. Cambridge: Cambridge University Press. ISBN 0-521-78239-2

[4] David R. DeVaux (1996), A tutorial in Authorware

[5] Moodle - A Free, Open Source Course Management System for Online Learning. oit.montclair.edu/documentation/moodle/What_is_Moodle.doc

[6] Steven Holzner (2002), Visual Basic .NET Black Book, Paraglyph Press, 2002 pp.800-810

[7] Thiru Thangarathinam(2009),Deploying ASP.NET ApplicatiosPart1WebMediaBrands Inc(2009) pp.5-10 